\title{
Supersonic Plasma Spray Deposition of CoNiCrAIY Coatings on Ti-6Al-4V Alloy
}

\author{
F. R. Caliari ${ }^{1}$ F. S. Miranda ${ }^{1}$ - D. A. P. Reis ${ }^{2}$ A. M. Essiptchouk ${ }^{3}$. \\ G. P. Filho ${ }^{1}$
}

Submitted: 26 October 2016/in revised form: 24 April 2017/Published online: 19 May 2017

(c) ASM International 2017

\begin{abstract}
Plasma spray is a versatile technology used for production of environmental and thermal barrier coatings, mainly in the aerospace, gas turbine, and automotive industries, with potential application in the renewable energy industry. New plasma spray technologies have been developed recently to produce high-quality coatings as an alternative to the costly low-pressure plasma-spray process. In this work, we studied the properties of as-sprayed CoNiCrAlY coatings deposited on Ti-6Al-4V substrate with smooth surface $\left(R_{\mathrm{a}}=0.8 \mu \mathrm{m}\right)$ by means of a plasma torch operating in supersonic regime at atmospheric pressure. The CoNiCrAlY coatings were evaluated in terms of their surface roughness, microstructure, instrumented indentation, and phase content. Static and dynamic depositions were investigated to examine their effect on coating characteristics. Results show that the substrate surface velocity has a major influence on the coating properties. The sprayed CoNiCrAlY coatings exhibit low roughness $\left(R_{\mathrm{a}}\right.$ of $\left.5.7 \mu \mathrm{m}\right)$, low porosity $(0.8 \%)$, excellent mechanical properties $\left(H_{\mathrm{it}}=6.1 \mathrm{GPa}, E_{\mathrm{it}}=155 \mathrm{GPa}\right)$, and elevated interface toughness $\left(2.4 \mathrm{MPa} \mathrm{m}^{1 / 2}\right)$.
\end{abstract}

\section{F. R. Caliari \\ felipercaliari@yahoo.com.br}

1 Centro de Ciência e Tecnologia de Plasmas e Materiais PlasMat, Instituto Tecnológico de Aeronáutica - ITA, São José dos Campos, SP 12228-900, Brazil

2 Instituto de Ciência e Tecnologia, Universidade Federal de São Paulo - UNIFESP, São José dos Campos, SP 12231-280, Brazil

3 Instituto de Ciência e Tecnologia, Univ. Estadual Paulista UNESP, São José dos Campos, SP 12247-004, Brazil
Keywords axial injection · CoNiCrAlY · overlay coating · supersonic plasma spray

\section{Introduction}

The bond coat is an important component of thermal barrier coating (TBC) systems, providing oxidation and hot corrosion resistance and reducing the thermal expansion mismatch between the ceramic layer and substrate. Typically, second-generation bond coats have composition based on MCrAlY (where $M=\mathrm{Co}, \mathrm{Ni}$ ). As described by Evans et al. (Ref 1), the microstructure and chemical stability affect the oxidation rate of the bond coat at its interface with the ceramic coating, where a thermally grown oxide (TGO) layer develops during application, affecting the lifetime of the TBC. In this sense, the porosity level, oxide content, surface roughness, stabilized phases, chemical composition distribution, and hardness are essential parameters to evaluate the quality of as-sprayed coatings (Ref 2-5).

Among several processing routes to obtain MCrAlY overlay coatings, thermal spray (TS) technologies such as high-velocity oxygen fuel (HVOF), low-pressure plasma spray (LPPS), cold gas dynamic spray (CGDS), and atmospheric plasma spray (APS) play a major role (Ref 6-9). HVOF and CGDS operate with high particle velocity, and intermediate-high and cold particle temperature, respectively. Conventional APS can provide high particle temperature and low-intermediate particle velocity. The industry has used LPPS when high-quality coatings are required, mainly because this process operates under vacuum and with a supersonic plasma jet. These characteristics allow production of coatings with low porosity and low oxide content, but its main drawback is the high cost associated 
with the vacuum system (Ref 5). HVOF is usually associated with formation of dense coatings, whereas APS is commonly associated with large-scale porosity and high oxide content (Ref 10, 11). However, previous studies (Ref 2, 12) have demonstrated a trade-off between porosity and oxide content of CoNiCrAlY coatings sprayed by HVOF.

An alternative for the production of high-quality coatings at lower cost is atmospheric plasma spray, when operating at increased particle velocity. In this context, new processes have been developed to meet this goal. Mauer et al. (Ref 13) demonstrated the feasibility of spraying CoNiCrAlY coatings with low porosity and oxide content using a Triplex Pro 210 with high-speed nozzle, a process called high-velocity atmospheric plasma spray (HV-APS). However, HV-APS demands elevated input power and high flow rate of shroud gas and suffers from the limitations imposed by the radial injection method. Therefore, we present herein an alternative plasma spray process to produce high-quality $\mathrm{CoN}$ iCrAlY coatings. This process, called high-velocity plasma spray (HVPS), operates in supersonic regime with axial injection of feedstock, and provides elevated plasma-particle heat transfer efficiency, resulting in lower input power requirements. The microstructural and mechanical properties of CoNiCrAlY coatings sprayed by HVPS on Ti-6Al$4 \mathrm{~V}$ alloy were investigated and compared with state-of-theart CoNiCrAlY coatings produced by thermal spray technologies.

\section{Experimental Procedures}

Deposition was performed on Ti-6Al-4V substrate (per UNS R56400) provided in annealed state with $\alpha+\beta$ equiaxed microstructure, average grain size of $51 \mu \mathrm{m}^{2}$, hardness of $2.7 \pm 0.1 \mathrm{GPa}$, and elastic modulus of 113.8 GPa. The surface of the substrate was machined using a milling cutter machine to obtain a smooth roughness profile. This was done intentionally to evaluate the contribution of adhesion mechanisms other than mechanical anchoring.

The powder used in this work was CoNiCrAlY alloy (Amperit 415.001, H.C. Starck) with nominal composition (wt.\%) of $38.5 \mathrm{Co}, 32 \mathrm{Ni}, 21 \mathrm{Cr}, 8 \mathrm{Al}, 0.5 \mathrm{Y}$, spherical shape (Fig. 1), and distribution with $d_{10}$ of $20 \mu \mathrm{m}, d_{50}$ of $30 \mu \mathrm{m}$, and $d_{90}$ of $45 \mu \mathrm{m}$.

The plasma spray experimental setup (Fig. 2) embodies a plasma torch with axial injection as described elsewhere (Ref 14) and a 4MP-dual (Sulzer Metco) powder feeder adapted to operate at $0.6 \mathrm{MPa}$. The speed of rotation and $X Y Z$ positioning of the samples were controlled by means of a specially designed sample holder. The plasma torch

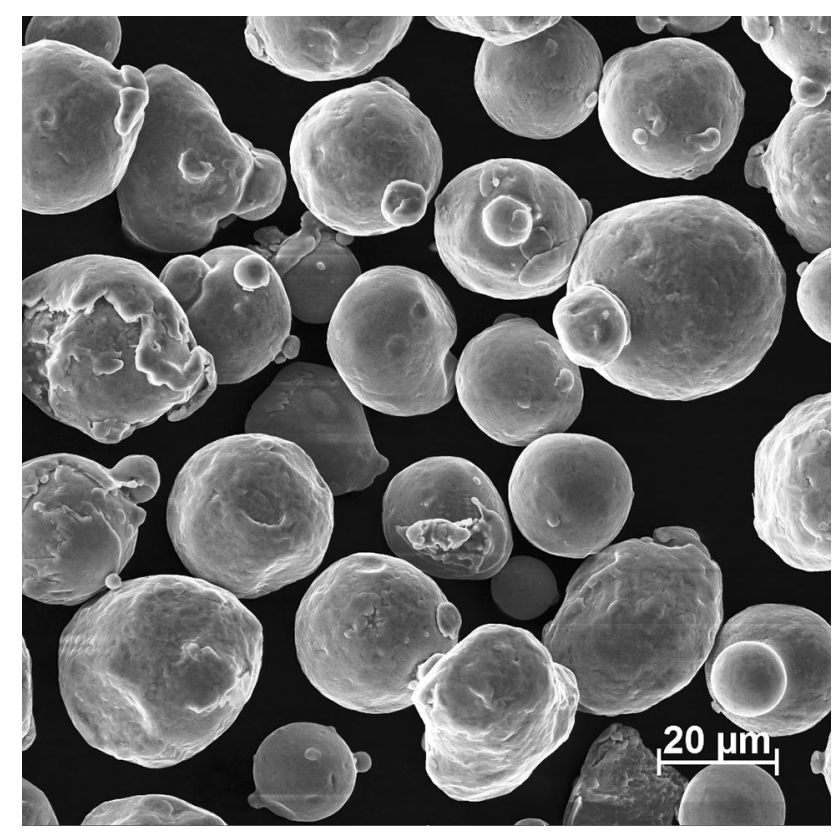

Fig. 1 Morphology of CoNiCrAlY powder

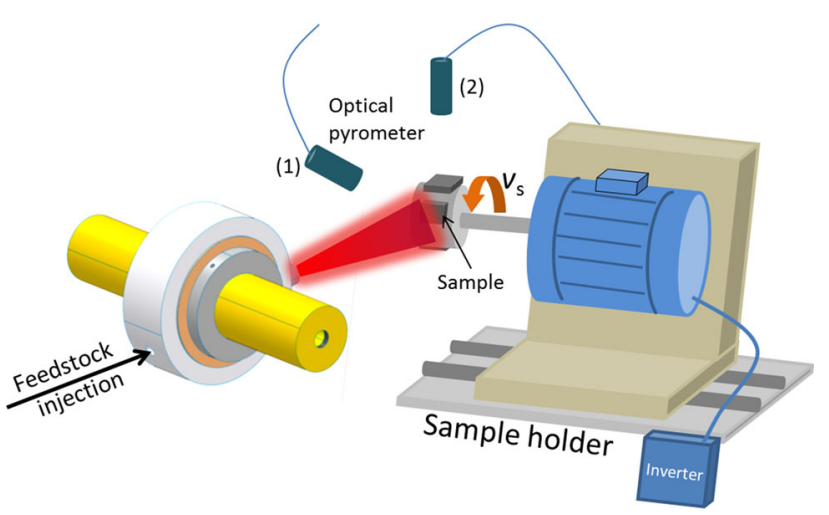

Fig. 2 Plasma spray experimental setup

remains at a fixed position during deposition. Prior to deposition, the substrate was preheated to $150{ }^{\circ} \mathrm{C}$ using the plasma jet. Experiments were performed under static condition (coating CS) where the samples remained at fixed position during deposition, and two dynamic conditions (CD) with surface velocity $\left(v_{s}\right)$ of $1.89 \mathrm{~m} / \mathrm{s}$ (coating CD1) or $0.57 \mathrm{~m} / \mathrm{s}$ (coating CD2). An optical pyrometer was used to measure the surface temperature, at either position (1) for static depositions or position (2) for dynamic depositions.

Table 1 details the parameters adopted for the $\mathrm{CoN}$ iCrAlY plasma spray depositions. In-flight particle velocity of $500 \mathrm{~m} / \mathrm{s}$ and particle temperature of $2330{ }^{\circ} \mathrm{C}$ were measured using a DPV-2000, at spray distance of $0.1 \mathrm{~m}$ from the nozzle. The roughness of the as-sprayed 
Table 1 Plasma spray parameters

\begin{tabular}{|c|c|c|c|c|c|c|c|c|c|}
\hline & Deposition method & $\begin{array}{c}\text { Working gas } \\
\text { feed rate, } \\
\mathrm{m}^{3} / \mathrm{s}\end{array}$ & Voltage, V & Current, A & $\begin{array}{c}\text { Standoff } \\
\text { distance, } \\
\mathrm{m}\end{array}$ & $\begin{array}{l}\text { Time of } \\
\text { deposition, } \\
\text { s }\end{array}$ & $\begin{array}{c}\text { Surface } \\
\text { velocity, } \\
\mathrm{m} / \mathrm{s}\end{array}$ & Preheating, ${ }^{\circ} \mathrm{C}$ & $\begin{array}{c}\text { Powder } \\
\text { feed rate, } \\
\mathrm{kg} / \mathrm{s}\end{array}$ \\
\hline Coating CS & Static & $5 \times 10^{-3}$ & 380 & 100 & 0.1 & 60 & 0 & 150 & $8.3 \times 10^{-5}$ \\
\hline Coating CD1 & Dynamic (300 RPM) & & & & & 360 & 1.89 & & \\
\hline Coating CD2 & Dynamic (90 RPM) & & & & & 360 & 0.57 & & \\
\hline
\end{tabular}

CoNiCrAlY coating was analyzed using a KLA-Tencor P7 profilometer using the following parameters: average roughness $\left(R_{\mathrm{a}}\right)$, root-mean-square roughness $\left(R_{\mathrm{q}}\right)$, skewness of roughness profile $\left(R_{\mathrm{sk}}\right)$, and maximum peak-valley height $\left(R_{z}\right)$. Preparation of cross-sections followed conventional metallographic procedures using epoxy resin for cold mounting in vacuum. The porosity and oxide content were evaluated by means of image analysis using ImageJ software. X-ray diffraction (XRD) analysis was performed using an X́Pert Powder from PANalytical from $2 \theta$ of $30^{\circ}$ to $80^{\circ}$ with step size of $0.02^{\circ}$ at $40 \mathrm{kV}$ and $50 \mathrm{~mA}$. The coating microstructure was observed by scanning electron microscopy (SEM) using a Tescan Vega 3 XMU, equipped with an energy-dispersive spectroscopy (EDS) detector. Instrumented indentation tests were performed on the cross-section of the coatings using a MCT NHT ${ }^{2}$ indentation tester with a Vickers indenter from Anton Paar to obtain values of hardness $\left(H_{\mathrm{it}}\right)$ and elastic modulus $\left(E_{\mathrm{it}}\right)$, considering a Poisson's ratio of 0.29. Measurements of interface toughness were carried out at 50, 100, 200, 300, and 500 gf using a Durascan 70 from Emcotest. At least five indentations were made for each load, at the coatingsubstrate interface, followed by measurements of the indenter half-diagonal $\left(a_{\mathrm{c}}\right)$ and crack length $(c)$.

\section{Results and Discussion}

\section{X-ray Diffraction}

XRD analysis of the CoNiCrAlY powder detected the $\gamma$ matrix (Co-Ni-Cr) stabilized along with small quantities of $\beta$-(Co,Ni)Al. After deposition via the HVPS process, a reduction of $\beta$-phase (near peak at $2 \theta=45^{\circ}$ ) was observed for both static and dynamic deposition (Fig. 3). This is due to the high particle temperature $\left(2330{ }^{\circ} \mathrm{C}\right)$, which promotes dissolution of the $\beta$-phase into the $\gamma$-matrix, and also to the fast cooling rates experienced by droplets upon impact on the substrate, preventing phase precipitation. On the other hand, during deposition of CoNiCrAlY by HVOF (Ref 15), the $\beta$-phase present in the feedstock is retained in the coating due to the high degree of unmelted particles. Richer et al. (Ref 16) described the absence of $\beta$-phase for

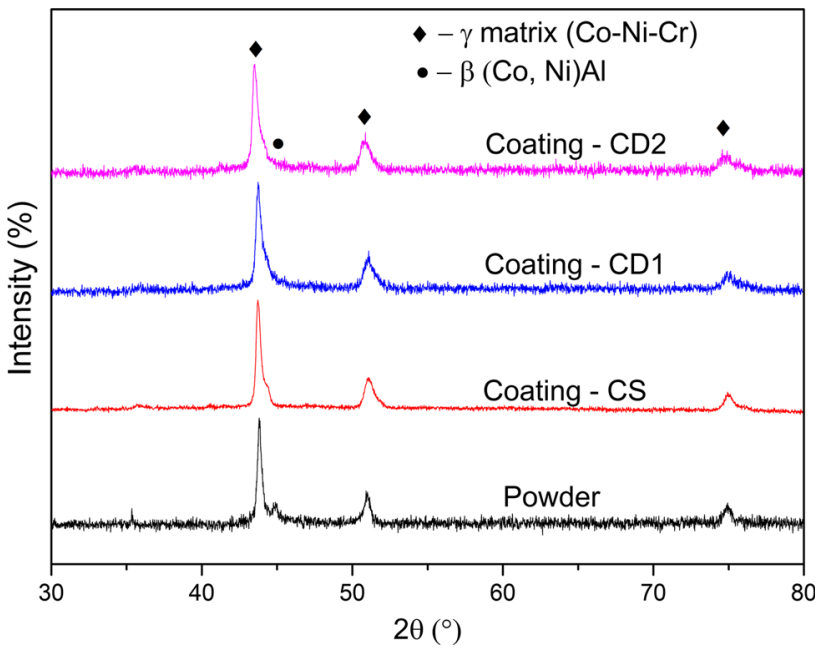

Fig. 3 XRD patterns of CoNiCrAlY powder and coatings

CGDS CoNiCrAlY coatings, but differently from the TS process with high particle temperatures, this is due to severe plastic deformation from high particle velocity. Mauer et al. (Ref 13) reported the beneficial effects of operating plasma spray in the supersonic regime for deposition of CoNiCrAlY coatings. Isothermal oxidation tests showed a higher oxidation rate of samples produced by LPPS in comparison with samples produced by the new process developed by the authors, called high-velocity atmospheric plasma spray (HV-APS).

\section{Surface Roughness}

The average roughness $\left(R_{\mathrm{a}}\right)$ of the substrate after milling was $0.8 \mu \mathrm{m}$; its three dimensional (3D) profile is presented in Fig. 4. Usually, adhesion of plasma spray coatings is associated with mechanical anchoring promoted by substrate roughness. Bahbou et al. (Ref 17) studied the adhesion of Tribaloy 800 coating deposited via plasma spray on Ti-6Al-4V substrate with average roughness between 3 and $4 \mu \mathrm{m}$, showing that the adhesion strength increased with $R_{\mathrm{a}}$. As reported by Hadad et al. (Ref 18), the adhesion strength depends on the coating thickness and interfacial 


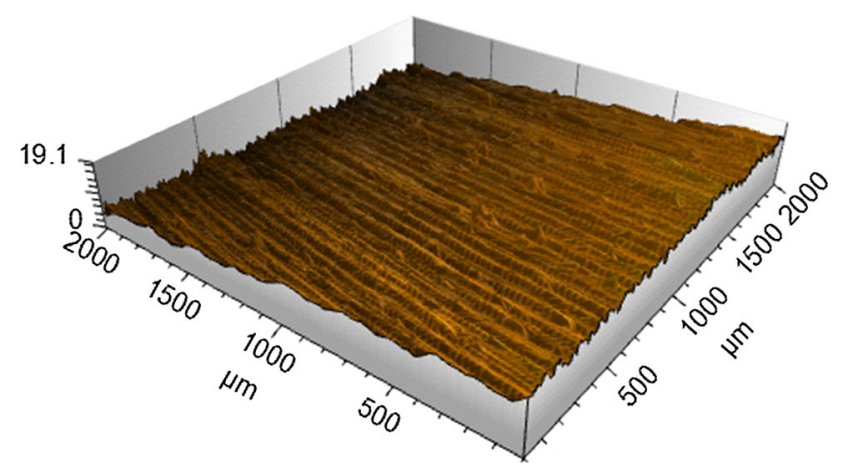

Fig. 4 Surface roughness profile of Ti-6Al-4V

roughness. For Ti-6Al-4V alloy, the interfacial toughness increases with increasing substrate roughness at lower coating thickness, while the opposite behavior is observed for higher thickness coatings. In the present study, the $R_{\mathrm{a}}$ of Ti-6Al-4V was kept at low values in comparison with the above-cited literature, to evaluate the adhesion mechanism promoted by the HVPS process other than mechanical anchoring.

The surface roughness profile of the CoNiCrAlY coatings is presented in Fig. 5, along with corresponding $R_{\mathrm{a}}$, $R_{\mathrm{q}}, R_{\mathrm{sk}}$, and $R_{z}$ values. As a general trend, dynamic deposition at 300 RPM (CD1) led to the highest values of $R_{\mathrm{a}}$ and $R_{\mathrm{q}}$, and the lowest value of $R_{\mathrm{sk}}$. Static and dynamic depositions diverged in terms of $R_{\mathrm{sk}}$ and $R_{z}$ values, with the static regime resulting in the lowest values. These differences are related to the surface temperature (Fig. 6), which is controlled by the droplet-substrate heat transfer and the surface velocity. As the in-flight particle properties were the same for all depositions, the increased surface velocity has a major effect on the droplet pile-up faults (porosity), hence promoting higher surface roughness. In comparison with the average roughness of CoNiCrAlY coatings reported in literature (Ref 2), one can observe that the results obtained by HVPS are rather lower (using coating $\mathrm{CD} 2$ as reference). The effect of the surface roughness of bond coats sprayed using different TS processes on the thermal cycle resistance of the TBC was studied by Ding et al. (Ref 19), considering HVOF, shroud air plasma spray (SAPS), and LPPS deposition methods. Those authors measured distinct values of maximum height $\left(R_{z}\right)$ for LPPS $(70 \mu \mathrm{m})$, SAPS $(47.7 \mu \mathrm{m})$, and HVOF $(29.3 \mu \mathrm{m})$, whereas $R_{z}$ values obtained in this study were between 27.9 and $39.0 \mu \mathrm{m}$ (Fig. 5). After testing the adhesive bond strength and thermal cycling resistance of the three CoNiCrAlY coatings, Ding et al. (Ref 19) found good levels of bond strength but quite divergent behavior in thermal cycling tests. As observed by the authors, SAPS CoNiCrAlY coating showed the highest thermal cycle lifetime, due to their suitable bond coat roughness and higher oxidation resistance. For HVOF bond coats, the lower particle temperature tends to cause elevated roughness $\left(R_{\mathrm{a}}\right.$ between 20 and $27 \mu \mathrm{m}$ ), and according to Tang et al. (Ref 20), this causes stress concentrations which lead to reduced thermal cycle resistance of the TBC.

\section{Coating Morphology via SEM/EDS}

SEM images of the coating surface highlight the presence of scale defects such as open pores and cracks, and elucidate the behavior of the particles upon impact and coating formation. From the top-view SEM images in Fig. 7, it can be noticed that the CoNiCrAlY powder was entirely melted during the depositions. The top view of coating CS in Fig. 7(a) shows smooth surface, well-connected splat boundaries with few round-shape particles. These surface characteristics are attributed to the high surface temperature (near $400{ }^{\circ} \mathrm{C}$ ) reached during the deposition. On the other hand, splat boundaries, open porosity, and cracks are present on the surface of coatings CD1 and CD2 (Fig. 7b and $\mathrm{c}$, respectively), along with splat fragmentation.

Backscattered electron (BSE) imaging of the crosssections (Fig. 8) reveals the effect of the surface velocity on the microstructure of the CoNiCrAlY coatings produced by HVPS. Figure 8 (a) shows that, when the surface velocity was zero (static deposition), the microstructure of the coating (CS) was very dense, with thickness of $300 \mu \mathrm{m}$ and detached from the substrate. This detachment can obviously be attributed to the limited adhesion between the Ti-6Al-4V substrate and CoNiCrAlY coating. Such low adhesion between these two materials has been reported by McKee and Luthra (Ref 21), who attributed this effect to the high thermal expansion mismatch between CoNiCrAlY $\left[15 \times 10^{-6}{ }^{\circ} \mathrm{C}^{-1}\right.$ (Ref 11)] and Ti-6Al-4V [9.4 $\times$ $10^{-6}{ }^{\circ} \mathrm{C}^{-1}$ (Ref 22)] and to the low ductility of the coating. Indeed, thermal stress caused by the elevated heat flux from impinging droplets and plasma jet to a lesser extent also promoted delamination upon cooling. The elastic modulus of coating CS (as calculated and discussed below) substantiates this hypothesis. The effect of thermal stress was maximized for coating CS, since the plasma torch and substrate remained at fixed position during this deposition. Detailed examination at the detached interface (Fig. 9) revealed that oxidation of Ti-6Al-4V occurred, which may have also contributed to the delamination. At 300 RPM, a coating (CD1) of $70 \mu \mathrm{m}$ was deposited, with low adherence between splats and to the substrate (Fig. 8b). The low adhesion observed for coating CD1 may be associated with formation of splats with splash-type morphology (Fig. 8d), due to the low surface temperature promoted by the high surface velocity $(1.89 \mathrm{~m} / \mathrm{s})$, as described by Morks et al. (Ref 23). Higher surface velocity also leads to a reduction in the number of droplets deposited, reducing the shot peen 

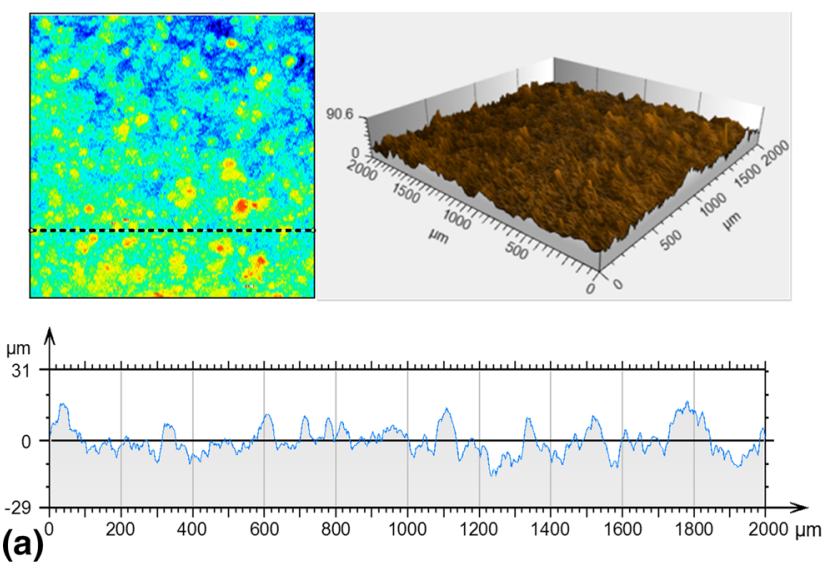

$($ a)
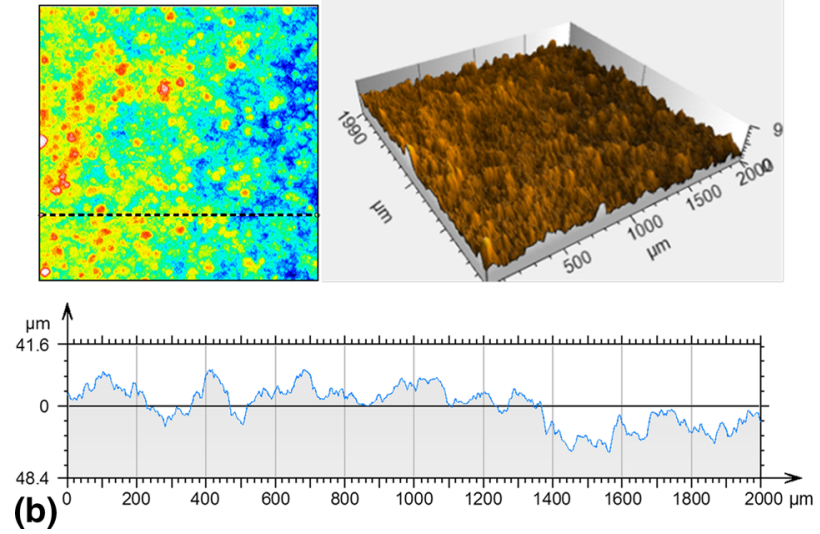

Fig. 5 Surface roughness of CoNiCrAlY coating deposited (a) statically (CS) and at (b) 300 RPM (CD1) and 90 RPM (CD2). (d) Values of $R_{\mathrm{a}}$, $R_{\mathrm{q}}, R_{z}$, and $R_{\mathrm{sk}}$

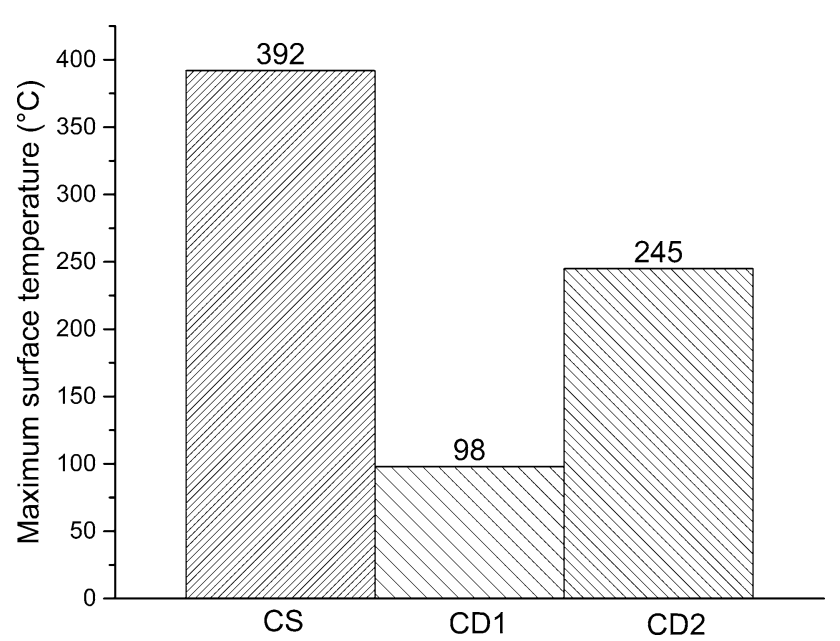

Fig. 6 Maximum surface temperature measured during HVPS deposition of CoNiCrAlY

effect caused by the impact of particles (Ref 24). Figure 6 presents the effect of high surface velocity on the surface temperature during deposition of coating $\mathrm{CD} 1$, which did not exceed $100{ }^{\circ} \mathrm{C}$ during the deposition. Hence, elevated rotation speed of the sample holder led to an excessive
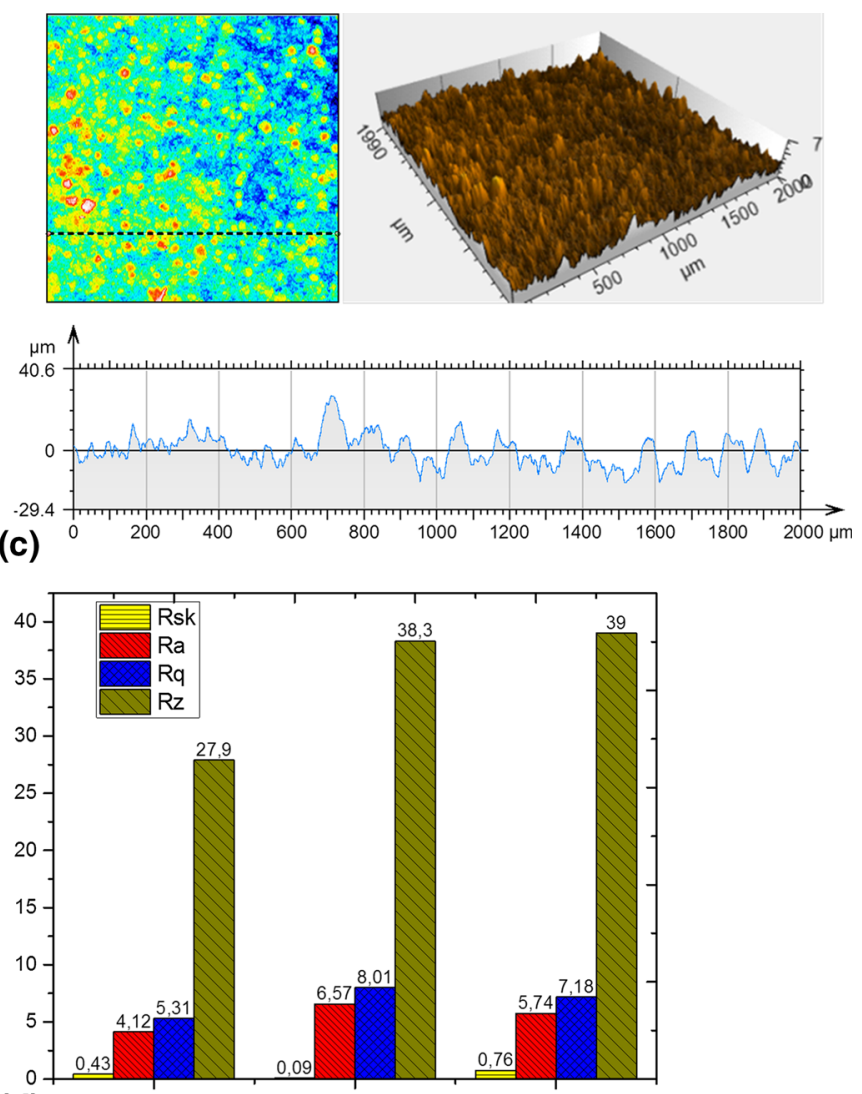

(d) Static deposition Deposition at 300 RPM Deposition at 90 RPM cooling effect, resulting in pile-up faults of the droplets, and ultimately in lower coating cohesion-adhesion. Longo (Ref 25) described that the range of surface velocity commonly adopted for HVOF and APS is 0.7 to 2 and 0.3 to $1.2 \mathrm{~m} / \mathrm{s}$, respectively. The surface velocity adopted for deposition of coating CD1 $(1.89 \mathrm{~m} / \mathrm{s})$ is therefore higher than expected for APS. The best result is obtained when the substrate is kept at surface velocity of $0.57 \mathrm{~m} / \mathrm{s}$. As observed in Fig. 8(c), coating CD2, with thickness of $57 \mu \mathrm{m}$, showed excellent contact between splats (small pores, evenly distributed) and was well adhered to the substrate. These results demonstrate that, at reasonable surface velocity, the beneficial effects provided by the HVPS process, namely ability to operate at both high particle velocity and temperature, and homogeneous processing of feedstock due to axial injection, can be obtained. Furthermore, the HVPS process operates at lower power level (total input power $38 \mathrm{~kW}$ ), in comparison with other supersonic plasma spray processes (Ref 13, 26), thanks to the high efficiency of the plasma-particle heat transfer.

The above-mentioned observations related to coating morphology are substantiated by the results for porosity and oxide content presented in Table 2. The kinetic regime 

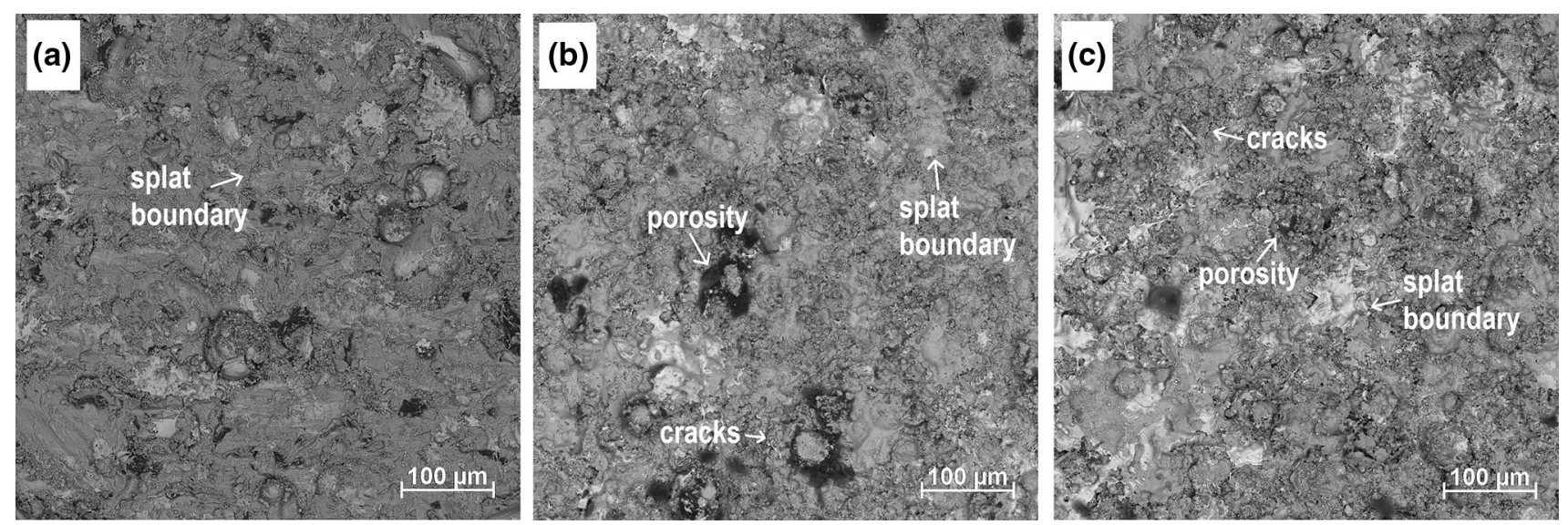

Fig. 7 Top-view SEM backscattered electron (BSE) images of coating (a) CS, (b) CD1, and (c) CD2
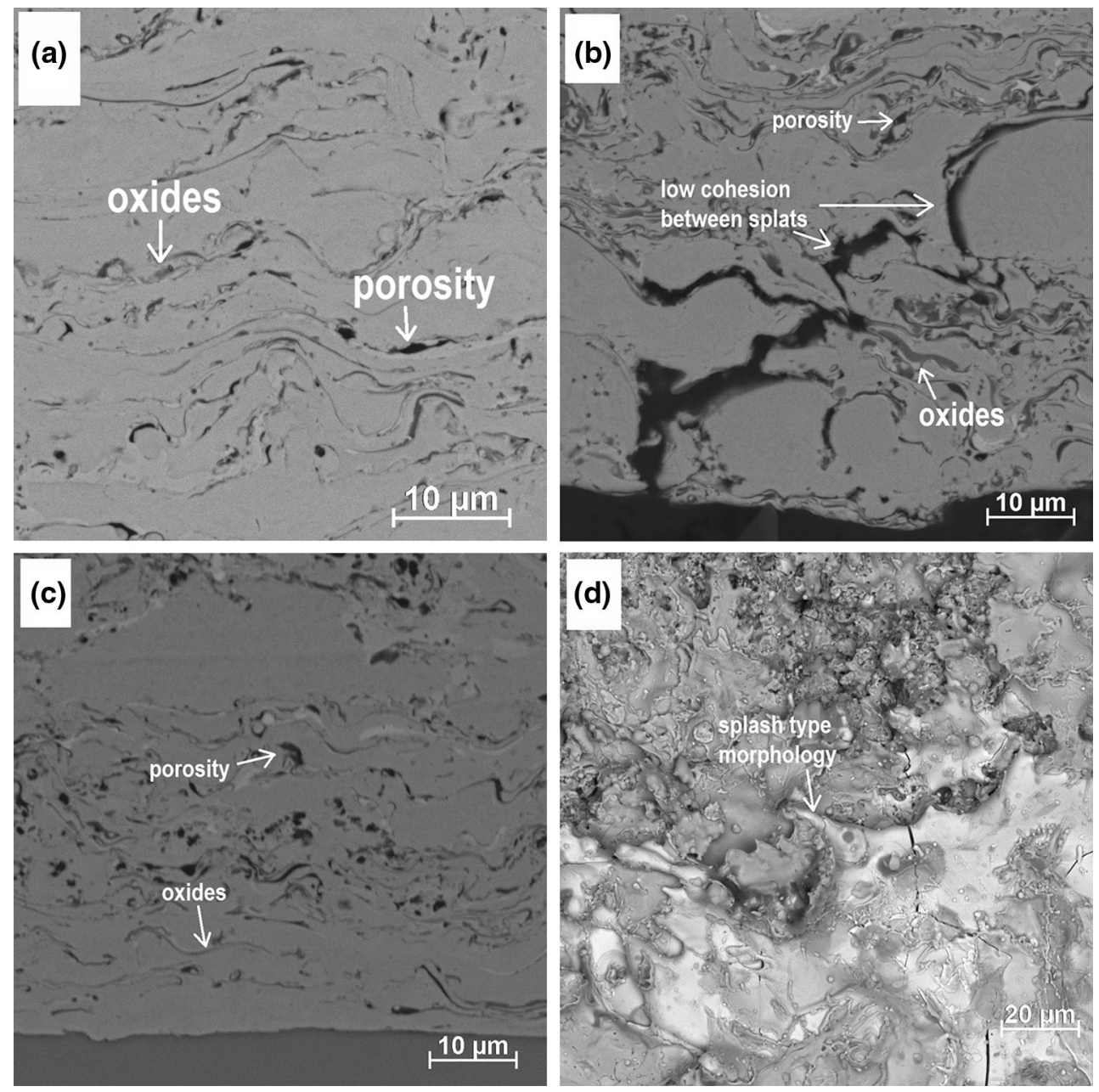

Fig. 8 SEM cross-section of coatings (a) CS, (b) CD1, and (c) CD2, and (d) detail of splash-type morphology in top view of CD1

provided by the HVPS process is high enough to produce coatings with low porosity, as observed from the result $(0.3 \%)$ for coating CS. This coating presented, however, a high level of oxidation $(4.7 \%)$ compared with the results of Richer et al. (Ref 6). Continuous exposure of the coating under formation to hot plasma gases contributed to this higher oxidation level. Nevertheless, the porosity and oxide content results for coatings CD1 and CD2 show that, once the surface velocity is promoted, it exerts a major influence on the coating microstructure. Deposition at surface 
Fig. 9 EDS results from delaminated region on coating CS

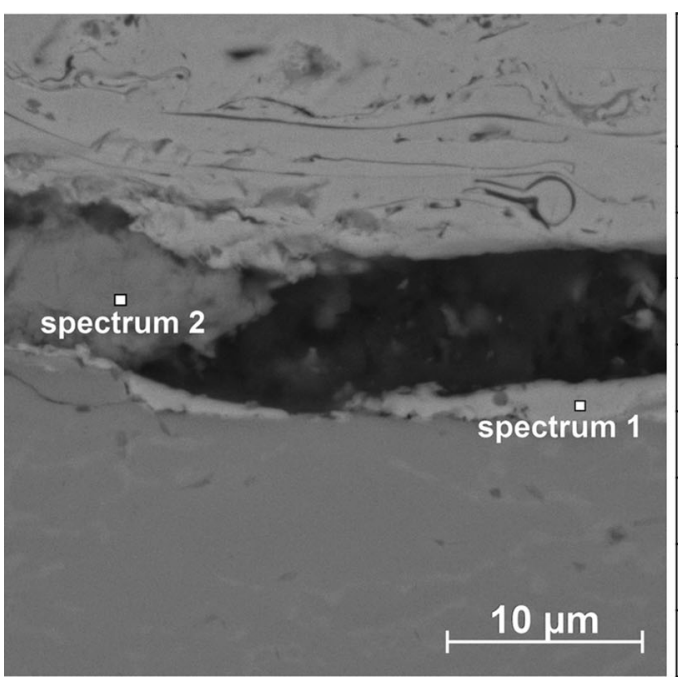

\begin{tabular}{|c|c|c|}
\hline \multirow{2}{*}{ Elements } & \multicolumn{2}{|c}{ Atoms (\%) } \\
\cline { 2 - 3 } & Spectrum 1. & Spectrum 2 \\
\hline $\mathrm{O}$ & 81.7 & 58.2 \\
\hline $\mathrm{Ti}$ & 8.6 & 26.0 \\
\hline $\mathrm{Co}$ & 3.2 & 4.1 \\
\hline $\mathrm{Ni}$ & 2.3 & 3.3 \\
\hline $\mathrm{Cr}$ & 1.3 & 3.2 \\
\hline $\mathrm{Al}$ & 2.0 & 3.9 \\
\hline $\mathrm{V}$ & - & 1.2 \\
\hline $\mathrm{Y}$ & 0.5 & 0.1 \\
\hline
\end{tabular}

Table 2 Porosity and oxide content of as-sprayed coatings

\begin{tabular}{lcr}
\hline & Porosity, \% & \multicolumn{1}{c}{ Oxides, \% } \\
\hline Coating CS & $0.3 \pm 0.1$ & $4.7 \pm 1.4$ \\
Coating CD1 & $2.7 \pm 1.3$ & $12.5 \pm 2.8$ \\
Coating CD2 & $0.8 \pm 0.3$ & $3.8 \pm 0.7$ \\
\hline
\end{tabular}

velocity of $1.89 \mathrm{~m} / \mathrm{s}$ (coating CD1) led to poor splat-splat contact, which resulted in the highest porosity (2.7\%) and oxidation content $(12.5 \%)$. By keeping the surface velocity at $0.57 \mathrm{~m} / \mathrm{s}$, low porosity $(0.8 \%)$ and the lowest oxide content (3.8\%) were obtained. The results for coating CD2 demonstrate that the HVPS process provides lower porosity, compared with APS, HVOF, CGDS or HV-APS (Ref $6,8,13$, and 27). Although the oxide content (3.8\%) of coating CD2 was lower than commonly obtained by APS (Ref 11), it is somewhat higher than the values obtained by Richer et al. (Ref 6) and similar to the values of Mauer et al. (Ref 28). The combination of high plasma temperature, high-efficiency heat transfer, and low powder feed rate contributed to in-flight particle overheating, therefore resulting in high level of oxide content in the coating. The low powder feed rate used in this work was due to limitations encountered in operating the modified 4 MP-dual powder feeder. Investigation of the influence of powder feed rate on the oxide content of coatings produced by HVPS will be carried out in the near future.

\section{Mechanical Properties}

Figure 10(a) and (b) shows the relationship of $H_{\text {it }}$ and $E_{\text {it }}$ with increasing indentation depth, obtained by means of a continuous multicycle method with load sequence of 100 , $168,235,302,369,437$, and $503 \mathrm{~N}$, as described elsewhere
(Ref 29). Both samples CS and CD2 showed a decrease of $H_{\text {it }}$ with increasing indentation depth until $1300 \mathrm{~nm}$, after which no decrease was observed for CS, whereas a slight decrease from 7 to $6 \mathrm{GPa}$ was detected for coating CD2. This distinct behavior of $E_{\mathrm{it}}$ observed for coatings CS and $\mathrm{CD} 2$ can be attributed to their different stiffness levels, as coating CS experienced higher thermal stress during deposition (near $400{ }^{\circ} \mathrm{C}$ ) compared with coating CD2 $\left(245^{\circ} \mathrm{C}\right)$. The latter observations are confirmed by the results for the elastic modulus $\left(E_{\mathrm{it}}\right)$, which was higher for coating CS than CD2. The lowest hardness value of coating CD1 reflects the results in Table 2, where the highest level of volumetric defects was found.

Single indentation tests were evenly distributed along the cross-section of the coatings, in order to evaluate the values of hardness and elastic modulus, and therefore the coating homogeneity, across the microstructure.

The load-displacement curves obtained via instrumented indentation of coating CS are presented in Fig. 11. From this relationship it was possible to obtain hardness $H_{\text {it }}$ of $8.5 \pm 2.0 \mathrm{GPa}$ and elastic modulus of $216.1 \pm$ $19.1 \mathrm{GPa}$. During the calculation of $H_{\mathrm{it}}$ and $E_{\mathrm{it}}$, it was noted that curves 2 and 5 exceeded the calibrated range $\left(h_{\mathrm{c}}=1396 \mathrm{~nm}\right)$. The displacement values of curves 2 and 5 are higher than those of other curves, which resulted in values of $H_{\text {it }}$ of 5.6 and $4.9 \mathrm{GPa}$, and $E_{\mathrm{it}}$ of 198.9 and $186.8 \mathrm{GPa}$, respectively.

Similarly to the discrepancy obtained in the calculation of $H_{\mathrm{it}}$ and $E_{\mathrm{it}}$ described above, coating CD1 presented the same behavior, except that this time the values of $h_{\mathrm{c}}$ surpassed the calibration limit for curves 1, 2, 3, 4, 5, 8, and 9 (Fig. 12). The values of $H_{\mathrm{it}}$ and $E_{\mathrm{it}}$ for coating CD1, i.e., $6.6 \pm 2.5$ and $150 \pm 36.8 \mathrm{GPa}$, presented greater dispersion in comparison with those for CS and CD2, which is directly related to the microstructure with more volumetric defects, such as porosity and oxide content. 


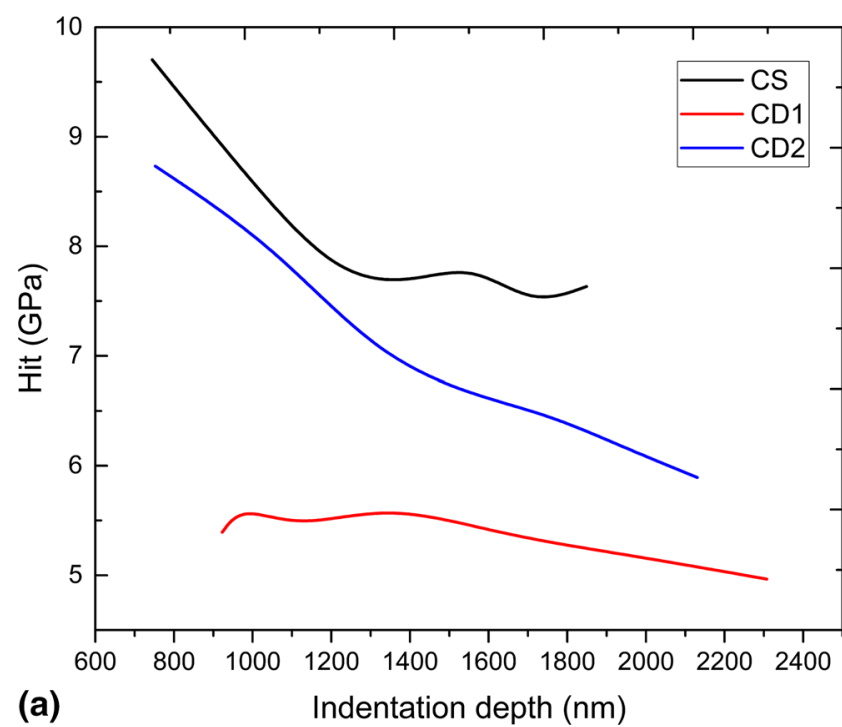

Fig. 10 Behavior of (a) $H_{\text {it }}$ and (b) $E_{\text {it }}$ at different indentation depths

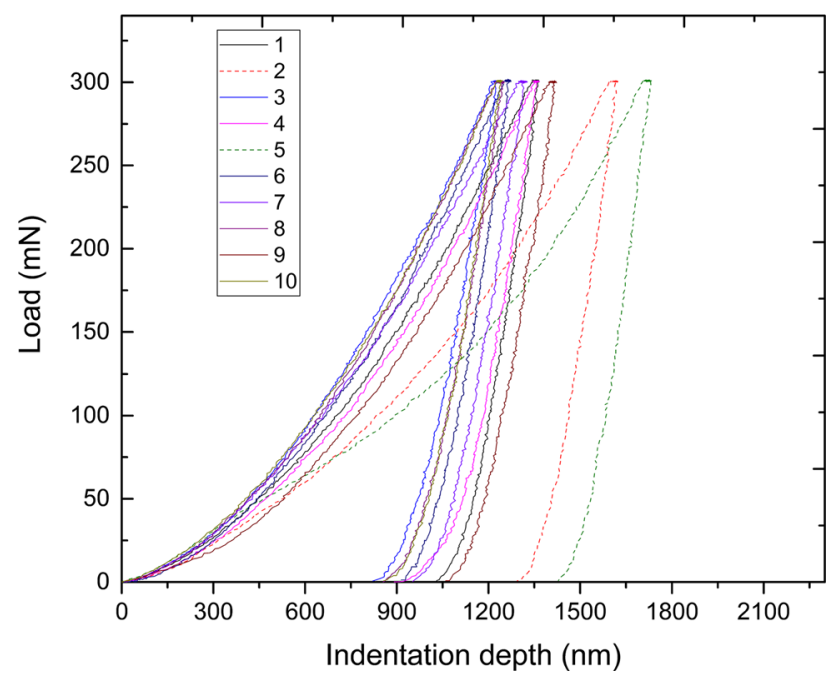

Fig. 11 Load-displacement curves for coating CS

The load-displacement curves of coating CD2 are presented in Fig. 13, with corresponding values of $H_{\text {it }}$ of $6.1 \pm 1.6 \mathrm{GPa}$ and $E_{\mathrm{it}}$ of $155 \pm 21.1 \mathrm{GPa}$. Here, curves 3, 6,7 , and 9 presented $h_{\mathrm{c}}$ deformation higher than $1396 \mathrm{~nm}$. Nonetheless, coating CD2 exhibited lower standard deviation compared with coating CD1, for both $H_{\text {it }}$ and $E_{\text {it }}$ values, indicating lower heterogeneity in the microstructure of coating CD2.

Using the APS process, Di Girolamo et al. (Ref 10) deposited a CoNiCrAlY coating with $4 \%$ porosity, mainly composed of $\gamma$-matrix, with hardness and elastic modulus of 3.5 and $131 \mathrm{GPa}$, respectively. In comparison with the values calculated for coating CD2, the values obtained by Di Girolamo et al. are rather lower. Rathod et al. (Ref 30), when studying the wear and corrosion resistance of CoNiCrAlY
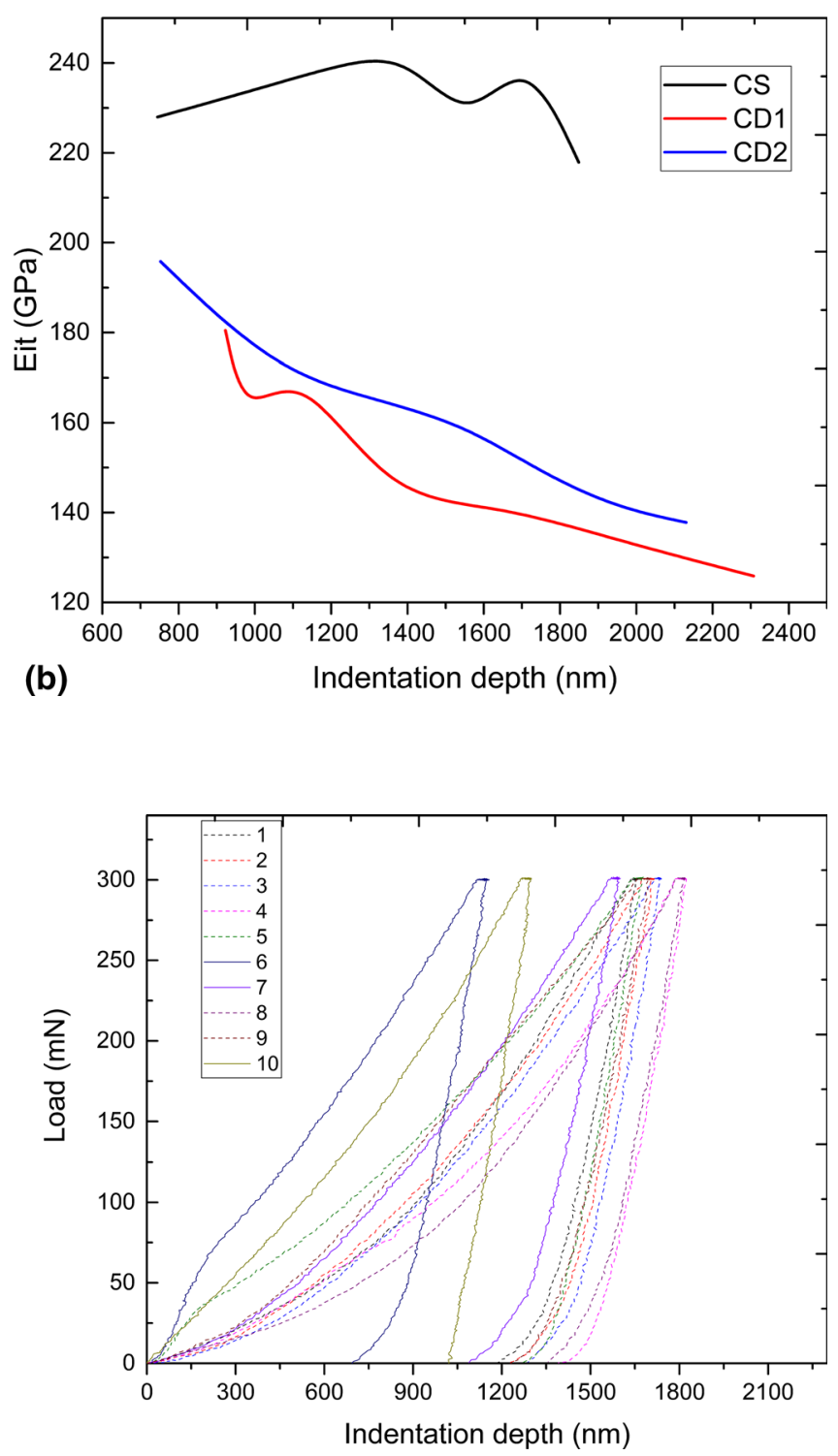

Fig. 12 Load-displacement curves for coating CD1

coatings deposited by HVOF and He-CGDS, obtained hardness and elastic modulus of 5.0, 6.6 and 119.1, 164.8 GPa, respectively. According to the results, the coating produced by CGDS using helium carrier gas, which had $H_{\text {it }}$ and $E_{\text {it }}$ values close to those of coating CD2, showed improved wear and corrosion resistance.

\section{Interface Indentation Toughness}

The interfacial adhesion of a CoNiCrAlY coating can be estimated by measuring the interfacial fracture toughness $\left(K_{\mathrm{ca}}\right)$, since this parameter is directly related to the critical indentation load $\left(P_{\mathrm{c}}\right)$, which in turn reflects the cracking resistance of the interface (Ref 31). Interfacial indentation tests were performed on coating CD2 only, as on the 


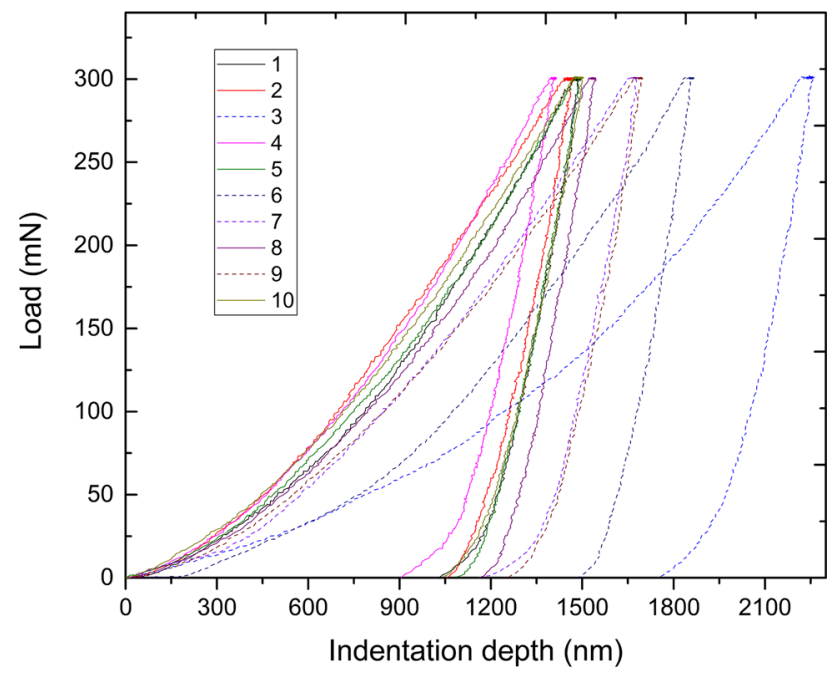

Fig. 13 Load-displacement curves for coating CD2

remaining samples the coating detached from the substrate during metallographic preparation. From Fig. 14, one can notice that the critical load $\left(P_{\mathrm{c}}\right)$ supported by the Ti-6Al4V/CoNiCrAlY interface on CD2 was $1.62 \mathrm{~N}$ (165.2 gf).

Following the equation proposed by Lesage and Chicot (Ref 17$)$, the apparent interfacial toughness $\left(K_{\mathrm{ca}}, \mathrm{MPa} \mathrm{m}^{1 /}\right.$ ${ }^{2}$ ) can be determined as

$K_{\mathrm{ca}}=0.015 \frac{P_{\mathrm{c}}}{a_{\mathrm{c}}^{3 / 2}}\left(\frac{E^{\prime}}{H}\right)_{\mathrm{i}}^{1 / 2}$,

where $a_{\mathrm{c}}$ is the half-diagonal of the indentation when $P=P_{\mathrm{c}}$, and $\left(E^{\prime} / H\right)_{\mathrm{i}}^{1 / 2}$ is the interface relation, which can be calculated from the hardness and elastic modulus of the substrate $(s)$ and coating $(c)$ using Eq 2:

$\left(\frac{E^{\prime}}{H}\right)_{\mathrm{i}}^{1 / 2}=\frac{\left(\frac{E^{\prime}}{H}\right)_{\mathrm{s}}^{1 / 2}}{1+\left(\frac{H_{\mathrm{s}}}{H_{\mathrm{c}}}\right)^{1 / 2}}+\frac{\left(\frac{E^{\prime}}{H}\right)_{\mathrm{c}}^{1 / 2}}{1+\left(\frac{H_{\mathrm{c}}}{H_{\mathrm{s}}}\right)^{1 / 2}}$.

Therefore, the apparent interface toughness for coating $\mathrm{CD} 2$ is $2.4 \mathrm{MPa} \mathrm{m}^{1 / 2}$.

Haddad et al. (Ref 18) investigated the adhesion of a NiCr80-20 metallic coating applied on Ti-6Al-4V titanium alloy. The authors calculated a value of interfacial toughness of $1.4 \mathrm{MPa} \mathrm{m}{ }^{1 / 2}$, considering that $\mathrm{NiCr} 80-20$ was deposited by flame spraying. Even though the substrate roughness used in the present work is lower $(0.8 \mu \mathrm{m})$ compared with that used by Haddad et al., the coating deposited by HVPS showed higher interface toughness. Despite the fact that, at lower surface roughness, the mechanical adhesion does not make a substantial contribution to coating adhesion, the good flattening of the droplets at the interface (Fig. 8c) and the compressive stress promoted by the high particle velocity may have contributed to the higher interface toughness.

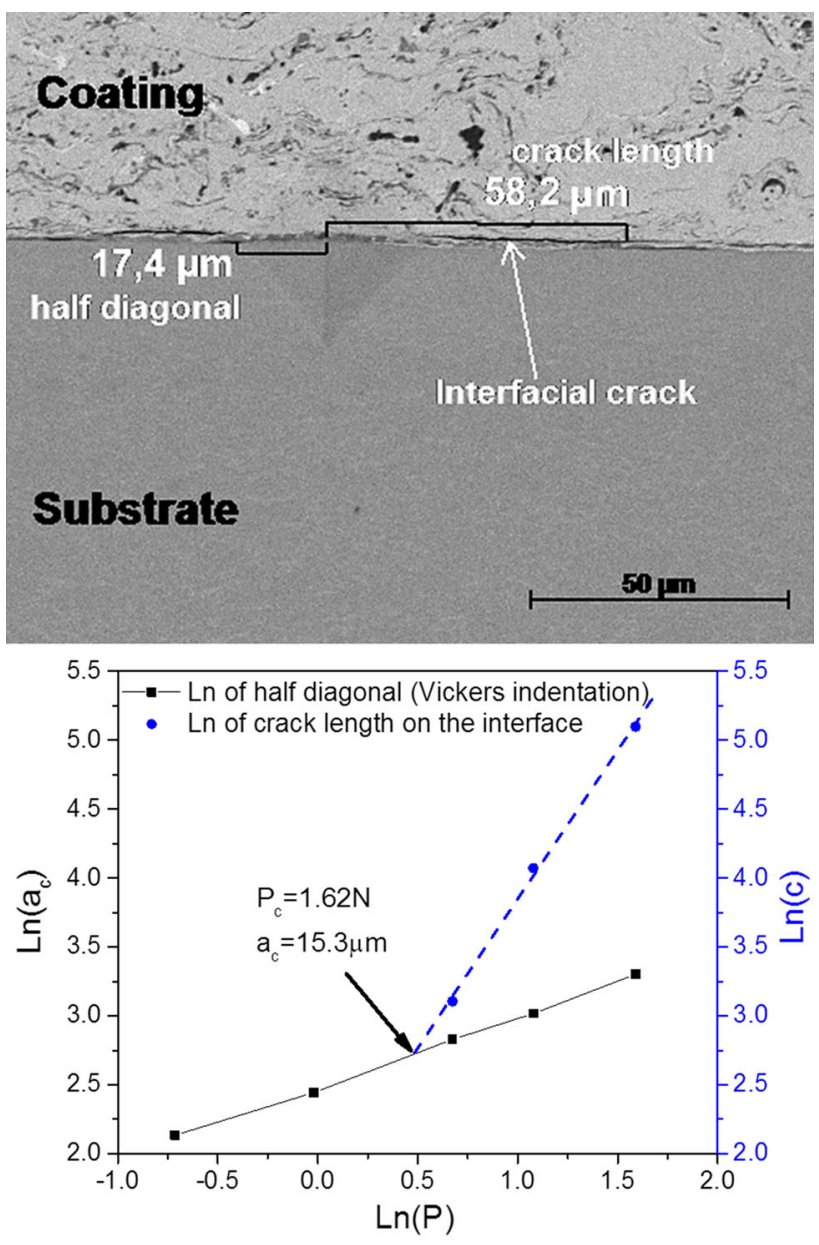

Fig. 14 Relationship between half-diagonal of indentation, crack length, and interface load for coating CD2, and image of interface indentation

\section{Conclusions}

A new supersonic plasma spray process (HVPS) is proposed as an alternative to produce high-quality coatings. This process promotes high particle velocity and temperature and allows axial feedstock injection. For this purpose, CoNiCrAlY powder with particle size distribution of 20 to $45 \mu \mathrm{m}$ was deposited on Ti-6Al-4V with $R_{\mathrm{a}}$ of $0.8 \mu \mathrm{m}$. HVPS depositions were performed at different surface velocities. The results show that, at surface velocity of $0.57 \mathrm{~m} / \mathrm{s}$, highquality CoNiCrAlY coating with low roughness $\left(R_{\mathrm{a}}=\right.$ $5.7 \mu \mathrm{m})$, high hardness $\left(H_{\mathrm{it}}=6.1 \mathrm{GPa}\right)$ and elastic modulus $\left(E_{\mathrm{it}}=155 \mathrm{GPa}\right)$, and low porosity $(0.8 \%)$ and oxide content $(3.8 \%)$ was deposited. Moreover, interfacial indentation tests revealed elevated interface toughness of $2.4 \mathrm{MPa} \mathrm{m}^{1 / 2}$, even though deposition was performed on a substrate with low roughness. The high degree of droplet flattening at the interface and the compressive stress produced by the high particle velocity contributed to obtain high coating adhesion. 
Thereby, HVPS represents a new cost-saving alternative to produce metallic coatings with improved high-temperature performance. This process operates with lower input power due to its elevated plasma-particle heat transfer efficiency. Further investigation to relate the effect of the powder feed rate on the oxide content of the CoNiCrAlY coating will be performed.

Acknowledgments The authors acknowledge financial support from FAPESP (Grant No. 2012/24851-7), CNPq, and CAPES.

\section{References}

1. A.G. Evans, D.R. Mumm, J.W. Hutchinson, G.H. Meier, and F.S. Pettit, Mechanisms Controlling the Durability of Thermal Barrier Coatings, Prog. Mater. Sci., 2001, 46, p 505-553

2. T. Mori, S. Kuroda, H. Murakami, H. Katanoda, Y. Sakamoto, and S. Newman, Effects of Initial Oxidation on $\beta$ Phase Depletion and Oxidation of CoNiCrAlY Bond Coatings Fabricated by Warm Spray and HVOF Processes, Surf. Coat. Technol., 2013, 221, p 59-69

3. A. Gil, V. Shemet, R. Vassen, M. Subanovic, J. Toscano, D. Naumenko, L. Singheiser, and W.J. Quadakkers, Effect of Surface Condition on the Oxidation Behaviour of MCrAlY Coatings, Surf. Coat. Technol., 2006, 201, p 3824-3828

4. S. Saeidi, K.T. Voisey, and D.G. McCartney, Mechanical Properties and Microstructure of VPS and HVOF CoNiCrAlY Coatings, J. Therm. Spray Technol., 2011, 20, p 1231-1243

5. M. Shibata, S. Kuroda, H. Murakami, M. Ode, M. Watanabe, and Y. Sakamoto, Comparison of Microstructure and Oxidation Behavior of CoNiCrAlY Bond Coatings Prepared by Different Thermal Spray Processes, Mater. Trans., 2006, 47, p 1638-1642

6. P. Richer, M. Yandouzi, L. Beauvais, and B. Jodoin, Oxidation Behaviour of CoNiCrAlY Bond Coats Produced by Plasma, HVOF and Cold Gas Dynamic Spraying, Surf. Coat. Technol., 2010, 204, p 3962-3974

7. M. Sone, H. Fukanuma, R. Huang, and N. Ohno, Comparison of the Characteristics of CoNicrAlY Coatings Prepared by Cold Spray and LPPS Process, p 283-286, in Thermal Spray 2012: Proceedings from the International Thermal Spray Conference and Exposition, May 21-24, 2012

8. V. Higuera, F.J. Belzunce, and J. Riba, Influence of the ThermalSpray Procedure on the Properties of a CoNiCrAlY Coating, Surf. Coat. Technol., 2006, 200, p 5550-5556

9. A. Kulkarni, J. Gutleber, S. Sampath, A. Goland, W.B. Lindquist, H. Herman, A.J. Allen, and B. Dowd, Studies of the Microstructure and Properties of Dense Ceramic Coatings Produced by High-Velocity Oxygen-Fuel Combustion Spraying, Mater. Sci. Eng. A, 2004, 369, p 124-137

10. G. Di Girolamo, M. Alfano, L. Pagnotta, A. Taurino, J. Zekonyte, and R.J.K. Wood, On the Early Stage Isothermal Oxidation of APS CoNiCrAlY Coatings, J. Mater. Eng. Perform., 2012, 21, p 1989-1997

11. T. Patterson, A. Leon, B. Jayaraj, J. Liu, and Y.H. Sohn, Thermal Cyclic Lifetime and Oxidation Behavior of Air Plasma Sprayed CoNiCrAlY Bond Coats for Thermal Barrier Coatings, Surf. Coat. Technol., 2008, 203, p 437-441

12. B. Rajasekaran, G. Mauer, and R. Vaßen, Enhanced Characteristics of HVOF-Sprayed MCrAlY Bond Coats for TBC Applications, J. Therm. Spray Technol., 2011, 20, p 1209-1216

13. G. Mauer, D. Sebold, R. Vaßen, E. Hejrani, D. Naumenko, W.J. Quadakkers, Impact of Processing Conditions and Feedstock
Characteristics on Thermally Sprayed MCrAlY Bondcoat Properties, Surface and Coatings Technology. Available online 26 August 2016, ISSN 0257-8972.

14. F.R. Caliari, F.S. Miranda, D.A.P. Reis, G.P. Filho, L.I. Charakhovskic, and A. Essiptchouk, Plasma Torch for Supersonic Plasma Spray at Atmospheric Pressure, J. Mater. Process. Technol., 2016, 237, p 351-360

15. S. Saeidi, K.T. Voisey, and D.G. McCartney, The Effect of Heat Treatment on the Oxidation Behavior of HVOF and VPS CoNiCrAlY Coatings, J. Therm. Spray Technol., 2009, 18, p 209-216

16. P. Richer, A. Zúñiga, M. Yandouzi, and B. Jodoin, CoNiCrAlY Microstructural Changes Induced During Cold Gas Dynamic Spraying, Surf. Coat. Technol., 2008, 203, p 364-371

17. M.F. Bahbou, P. Nylen, and J. Wigren, Effect of Grit Blasting and Spraying Angle on the Adhesion Strength of a PlasmaSprayed Coating, J. Therm. Spray Technol., 2004, 13, p 508-514

18. M. Hadad, G. Marot, P. Démarécaux, J. Lesage, J. Michler, and S. Siegmann, Adhesion Tests for Thermal Spray Coatings: Application Range of Tensile, Shear and Interfacial Indentation Methods. Thermal Spray 2005: Thermal Spray Connects: Explore Its Surfacing Potential!, E. Lugscheider, Ed., May 2-4, 2005 (Basel, Switzerland), DVS-German Welding Society, 2005, p. 759-764, ISBN 3-87155-793-5.

19. Z. Ding, R. Knight, and W. Smith, Effect of Bond Coat Processes and Surface Characteristics on the Failure Mechanism of Thermal Barrier Coatings. Thermal Spray 2001: New Surfaces for a New Millennium, C.C. Berndt, K.A. Khor, and E.F. Lugscheider, Ed., ASM International, Singapore, 2001, p 173-177

20. J.J. Tang, Y. Bai, K. Liu, P. Zhang, B.Q. Li, and J.F. Yang, Microstructural Evolution of SAPS/HVOF CoNiCrAlY Alloy Coating During Thermal Cycling Test, Oxid. Met., 2016, 86, p 75-87

21. D.W. McKee and K.L. Luthra, Plasma-Sprayed Coatings for Titanium Alloy Oxidation Protection, Surf. Coat. Technol., 1993, 56, p 109-117

22. ASM Handbook, Volume 02 - Properties and Selection: Nonferrous Alloys and Special-Purpose Materials (1990), by Committee, ASM International Handbook, p. 1856

23. M.F. Morks, Y. Tsunekawa, M. Okumiya, and M.A. Shoeib, Splat Morphology and Microstructure of Plasma Sprayed Cast Iron with Different Preheat Substrate Temperatures, J. Therm. Spray Technol., 2002, 11, p 226-232

24. H.-D. Steffens and K. Nassenstein, Influence of the Spray Velocity on Arc-Sprayed Coating Structures, J. Therm. Spray Technol., 1999, 8, p 454-460

25. F.N. Longo, Coating Processing, Handbook of Thermal Spray Technology, ASM International, Singapore, 2004

26. S. Zhu and B.S. Xu, High-Performance Ceramic Coatings Sprayed Via Novel Supersonic Plasma Spraying System, Key Eng. Mater., 2005, 280-283, p 1203-1260

27. K. Murugan, A. Ragupathy, V. Balasubramanian, and K. Sridhar, Optimizing HVOF Spray Process Parameters to Attain Minimum Porosity and Maximum Hardness in WC-10Co-4Cr Coatings, Surf. Coat. Technol., 2014, 247, p 90-102

28. G. Mauer, D. Sebold, and R. Vaßen, MCrAlY Bondcoats by High-Velocity Atmospheric Plasma Spraying, J. Therm. Spray Technol., 2014, 23, p 140-146

29. Advanced Mechanical Surface Testing. Characterization of Thermal Spray Coatings by Instrumented Indentation and Scratch Testing Part II: Indentation of Plasma Sprayed Coatings. Application Report G71-IA-032-EN-A, Anton Paar

30. W.S. Rathod, A.S. Khanna, R.C. Rathod, and S.G. Sapate, Wear and Corrosion Behavior of CoNiCrAlY Bond Coats, J Inst Eng India Ser C, 2014, 95, p 261-271

31. J. Lesage and D. Chicot, Models for Hardness and Adhesion of Coatings, Surf. Eng., 1999, 15, p 447-453 